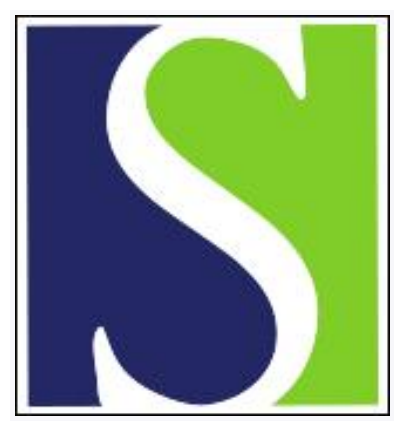

Scand J Work Environ Health 2003;29(1):60-63

https://doi.org/10.5271/sjweh.705

Issue date: Feb 2003

Diffuse pleural fibrosis-an unreliable indicator of heavy asbestos exposure?

by Smith KA, Sykes LJ, McGavin CR

Affiliation: Department of Respiratory Medicine, Derriford Hospital, Plymouth PL6 8DH, United Kingdom.

Refers to the following text of the Journal: 1997;23(4):311-316

Key terms: asbestos exposure; asbestosis; diffuse pleural fibrosis; lung cancer; pleural plaque

This article in PubMed: www.ncbi.nlm.nih.gov/pubmed/12630437 


\title{
Diffuse pleural fibrosis-an unreliable indicator of heavy asbestos exposure?
}

\author{
by Katharine A Smith, MRCP, ${ }^{1}$ Lisa J Sykes, MRCP, ${ }^{1}$ Clive R McGavin, MD ${ }^{1}$
}

\begin{abstract}
Smith KA, Sykes LJ, McGavin CR. Diffuse pleural fibrosis-an unreliable indicator of heavy asbestos exposure? Scand J Work Environ Health 2003;29(1):60-63.

Objectives This study aimed at testing the hypothesis that diffuse pleural fibrosis is associated with a heavier exposure to asbestos than that of benign pleural plaques, and hence diffuse pleural fibrosis can be used as a marker of heavy exposure.

Methods Asbestos burden was estimated for 192 naval dockyard workers (96 with diffuse pleural fibrosis, 96 with plaques) by calculating the exposure ratings from the trade and the years spent in that trade. In 53 cases the diffuse pleural fibrosis was bilateral.

Results No difference was found in the mean estimated asbestos burden between all diffuse pleural fibrosis and plaques, nor between plaques and unilateral and bilateral diffuse pleural fibrosis, analyzed separately by a onefactor analysis of variance. The mean asbestos burden was significantly greater for bilateral than for unilateral diffuse pleural fibrosis. A wide spread of asbestos exposure was noted among the men with diffuse pleural fibrosis.

Conclusions Diffuse pleural fibrosis may arise after widely varying exposure to asbestos. The mean exposure ratings for diffuse pleural fibrosis do not differ from those for pleural plaques, although the ratings are significantly higher for men with bilateral diffuse pleural fibrosis than for those with unilateral diffuse pleural fibrosis. Diffuse pleural fibrosis cannot be used as a reliable marker of heavy asbestos exposure.
\end{abstract}

Key terms asbestosis, lung cancer, pleural plaques.

It has been suggested that the amount of asbestos exposure required to cause diffuse pleural fibrosis is high, of the same order as that causing asbestosis and more than that required for the development of pleural plaques (1). As a result, diffuse pleural fibrosis has been used as a marker of heavy exposure, and this use is of relevance in assigning lung cancer to asbestos exposure. An expert group (1) considered this attribution and drew up the Helsinki criteria, which state "low exposure ... may induce pleural plaques. For diffuse pleural fibrosis, higher exposure levels may be required" and "bilateral diffuse pleural fibrosis is often associated with moderate or heavy exposure, as is seen in cases with asbestosis, and should be considered accordingly in terms of attribution [p 314]." In 1984, the Industrial Injuries Advisory Council (2) of the United Kingdom recommended that lung cancer in the presence of bilateral diffuse pleural fibrosis should be recognized as an industrial tumor, but it revoked an earlier decision that the presence of plaques alone should qualify a tumor for industrial status.

This study compares estimated asbestos burden in a well-defined group of men who had worked in a British naval dockyard and who had diffuse pleural fibrosis or plaques.

\section{Subjects and methods}

The subjects were men who had been exposed to asbestos in the Royal Naval Dockyard, Devonport, England. They had been noted to have pleural disease, usually by routine radiography, and had been examined for medical reports. One experienced observer (CM) had taken detailed occupational histories, examined the men, and read current plain posteroanterior chest radiographs.

Reprint requests to: Dr CR McGavin, Chest Clinic, Derriford Hospital, Plymouth PL6 8DH, United Kingdom. [E-mail: clive.mcgavin@phnt.swest.nhs.uk] 
We examined the records of all the men with diffuse pleural fibrosis (with or without pleural plaques) over a 20 -year period, starting in 1981, and a similar number of randomly selected records of men with plaques alone. We excluded those for whom there was an alternative cause for pleural fibrosis, such as autoimmune disease, tuberculosis or trauma, and those with additional asbestos exposure outside of the dockyard. None of the men were considered to have asbestosis on clinical or radiological grounds, although computerized scanning was not carried out. One observer interpreted the pleural abnormality by using the same criteria for distinguishing between diffuse pleural fibrosis and plaques as those described by Hillerdal (3). The main features of differentiation are that plaques are well defined, are sharply demarcated against the lung parenchyma, and do not affect the costophrenic recesses; diffuse pleural fibrosis, on the other hand, typically affects the costophrenic recesses, is less well demarcated, and blends more diffusely with the lung. Rounded atelectasis, "crow's feet" and apical fibrosis are features of diffuse pleural fibrosis but not of pleural plaques.

We assessed the asbestos burden by calculating an exposure rating for each case from the detailed work record. We relied on the previously described coding of all the trades in the Devonport dockyard according to the intensity of the exposure measured (4) (table 1); this intensity code was multiplied by years in that trade to give an exposure rating. When men had worked in more than one trade, the exposure ratings of the occupations were calculated and summed.

A detailed description of asbestos usage in the Devonport dockyard has been published earlier (5). From the 1960s on, alternative nonasbestos insulation materials have been introduced, and respiratory protection has been gradually enforced. However, it has been apparent that there were ample opportunities for exposure to asbestos dust through to the 1970s (CM, personal observation). A detailed study in 1971 described radiological abnormalities attributable to asbestos inhalation (6), and subsequently all the male dockyard workers were invited to complete a respiratory questionnaire and undergo chest radiography. For the purposes of this study it has been considered that exposure effectively ceased by 1972 . The decision to use this year as the cut-off point for asbestos exposure was somewhat arbitrary, but it was based on knowledge of work practices within the dockyard and on discussions with large numbers of workers from the yard. Statistical analyses were performed with SPSSv10.1 or Excel (SPSS Inc, Chicago, IL, USA, 2001).

\section{Results}

The records of 96 cases of diffuse pleural fibrosis (53 bilateral) and 96 cases of pleural plaques were analyzed. There were no significant differences between the groups with regard to age or the time between the first exposure to asbestos and consultation (table 2).

The mean asbestos burden for plaques and all cases of diffuse pleural fibrosis was compared using an independent sample t-test with degrees of freedom (df) adjusted for unequal variances (table 3 ). There was evidence of nonnormality, but the sample sizes were deemed large enough for parametric testing. No evidence of a difference in the means was found $(t=1.045$. $\mathrm{df}=179, \mathrm{P}=0.30$ ).

Plaques were compared with unilateral and bilateral diffuse pleural fibrosis separately using a one-factor analysis of variance. Because of the strong evidence of unequal variances in the three groups (Levene's test

Table 1. Asbestos exposure code by occupation

\begin{tabular}{cl}
\hline Code & Occupation \\
\hline 1 & Office work, messenger, outstation personnel \\
2 & $\begin{array}{l}\text { All industrial work ashore, nonindustrial supervisory staff with } \\
\text { very occasional exposure afloat }\end{array}$ \\
5 & $\begin{array}{l}\text { Foundry worker, Royal Navy engineroom branch } \\
10\end{array}$ \\
& $\begin{array}{l}\text { Laborer or skilled laborer afloat, joiner, coppersmith, riveter, } \\
\text { plumber, caulker, burner driller, shipfitter, engine fitter, }\end{array}$ \\
12 & electrical fitter, slinger \\
15 & Poilermaker, shipwright, welder \\
20 & Sainter, mason, furnace bricklayer \\
25 & Lagger afloat and ashore, asbestos sprayer or stripper \\
\hline
\end{tabular}

Table 2. Age and years since first exposure to asbestos.

\begin{tabular}{|c|c|c|c|c|c|c|c|}
\hline & \multirow[t]{2}{*}{$\mathrm{N}$} & \multicolumn{3}{|c|}{ Age (years) } & \multicolumn{3}{|c|}{ Time since first exposure (years) } \\
\hline & & Mean & SD & Range & Mean & SD & Range \\
\hline Pleural plaques & 96 & 58.0 & 8.0 & $43-75$ & 40.0 & 8.4 & $22-59$ \\
\hline \multicolumn{8}{|c|}{ Diffuse pleural fibrosis } \\
\hline $\begin{array}{l}\text { Unilateral } \\
\text { Bilateral }\end{array}$ & $\begin{array}{l}53 \\
43\end{array}$ & $\begin{array}{l}56.9 \\
62.3\end{array}$ & $\begin{array}{l}9.8 \\
9.5\end{array}$ & $\begin{array}{l}37-78 \\
44-84\end{array}$ & $\begin{array}{l}38.6 \\
41.1\end{array}$ & $\begin{array}{l}11.5 \\
12.0\end{array}$ & $\begin{array}{l}18-62 \\
15-68\end{array}$ \\
\hline All cases & 96 & 59.9 & 10.0 & $37-84$ & 39.9 & 11.8 & $15-68$ \\
\hline
\end{tabular}


Table 3. Asbestos exposure ratings by group.

\begin{tabular}{lcrrr}
\hline & $\mathrm{N}$ & \multicolumn{3}{c}{ Rating } \\
\cline { 2 - 5 } & & Mean & SD & Range \\
\cline { 2 - 5 } & & & \\
\cline { 2 - 5 } Pleural plaques & 96 & 153.0 & 97.9 & $10-372$ \\
$\begin{array}{l}\text { Diffuse pleural fibrosis } \\
\quad \text { Unilateral }\end{array}$ & 53 & 130.6 & 86.6 & $10-372$ \\
$\quad$ Bilateral & 43 & 202.0 & 143.0 & $10-600$ \\
All cases & 96 & 170.0 & 126.2 & $10-600$ \\
\hline
\end{tabular}

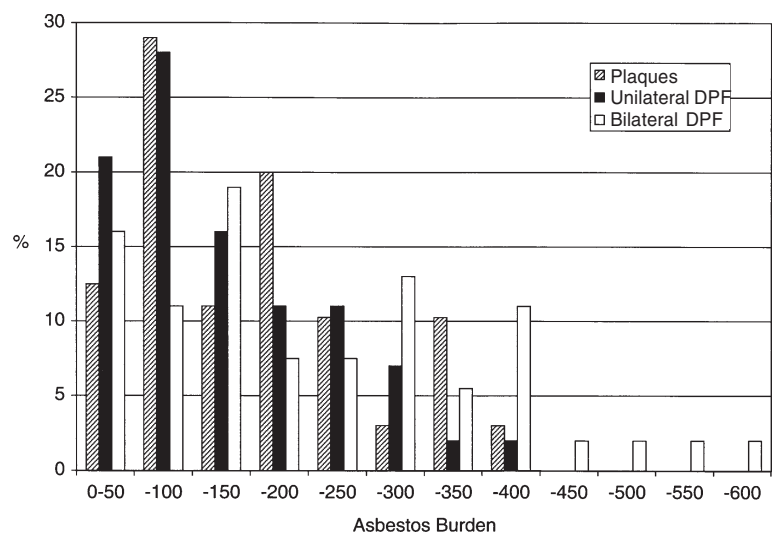

Figure 1. Distribution of the asbestos rating by group, expressed as the percentage of that group. (DPF = diffuse pleural fibrosis)

$\mathrm{P}<0.001$ ), $\log$ s of asbestos burdens were used (Levene's test on $\log$ data $\mathrm{P}=0.46$ ). The analysis of variance showed no significant difference between the mean asbestos burdens in plaques or unilateral or bilateral diffuse pleural fibrosis $(\mathrm{F} 2,189=2.56, \mathrm{P}=0.08)$. However a t-test (adjusted for unequal variances) comparing unilateral with bilateral diffuse pleural fibrosis found strong evidence suggesting that men with bilateral disease had had significantly more exposure than those with unilateral disease $(\mathrm{t}=2.86, \mathrm{df}=88, \mathrm{P}=0.004)$.

It is worth noting that Levene's test for the equality of variances demonstrated a significant difference in the standard deviations, diffuse pleural fibrosis having a greater standard deviation-indicating a wider range of dust exposure (figure 1).

\section{Discussion}

This study examined the asbestos burden in a homogeneous and defined workforce whose work practices and dust exposure have been previously documented in detail by the Medical Research Unit of the Devonport dockyard (4). The validity of this study relies on the estimation of dust burden by means of the exposure code. Rossiter and his colleagues state (4) that "the exposure codes were chosen after a long study of asbestos usage and exposure in the (Devonport) dockyard by consulting experienced practitioners in this area and many of the workers [p 832]." Dust levels have been measured in a wide variety of settings aboard naval vessels under refit, and examples of the ranges of levels have been given by Harries (7).

Wagner and his colleagues (8) used the exposure ratings in a study of correlation between lung fiber content and disease among naval dockyard workers. They found a good relation between the severity of lung pathology (asbestosis), the exposure rating, and the fiber content of the lungs in 333 specimens from the Devonport dockyard. The mean exposure rating rose from 212 for the men with no asbestosis and a fiber count of $25 \times 10^{6} / \mathrm{g}$ dry lung tissue to 495 among those with marked or severe asbestosis and a mean fiber count of $2732 \times 10^{6} / \mathrm{g}$ dry lung tissue. These observations support the exposure code. Furthermore, the exposure ratings in our study ranged from $<50$ up to 600 , indicating that we had included men with a very wide range of exposure, as opposed to only the heavily exposed with high dust burdens.

In our current study, all the work histories and all the radiographic readings were made by a single observer, and they were analyzed retrospectively. We therefore believe that a valid comparison has been made between asbestos burden in the two groups of men with benign pleural disease.

We found no evidence to suggest that the mean exposure to asbestos among the men with diffuse pleural fibrosis differed from that of pleural plaques. There is, therefore, no justification for using the presence of diffuse pleural fibrosis as a surrogate marker for heavy exposure to asbestos. This practice has implications in the debate about whether or not a given lung cancer has an industrial cause.

Because of its design, this study cannot address the question of the amount of asbestos required to cause diffuse pleural fibrosis as compared with the amount required to cause plaques; the problem which it addresses is, given the availability of a chest radiograph of an asbestos worker with diffuse pleural fibrosis, "Can deductions be made about the amount of dust that the worker has inhaled?" It is apparent that the presence of diffuse pleural fibrosis is no better a marker of heavy exposure than plaques are, and it is less reliable than a well-documented industrial history.

\section{Acknowledgments}

We acknowledge the scientific work carried out in the Medical Research Unit of the Devonport dockyard. The statistical analysis was performed by Dr S Shaw of the 
University of Plymouth, and it was funded by charitable chest clinic funds.

\section{References}

1. - - Asbestos, asbestosis and cancer: the Helsinki criteria for diagnosis and attribution [consensus report]. Scand J Work Environ Health 1997;23:311-6.

2. Industrial Injuries Advisory Council. Asbestos-related diseases without asbestosis. London: Her Majesty's Stationery Office; 1984. Cmnd 91.

3. Hillerdal G. Pleural lesions and the ILO classification: the need for a revision. Am J Ind Med 1991;19:125-30.

4. Rossiter CE, Coles RM, Jackaman I. HM Naval Base, Devonport: lung cancer and mesothelioma case control studies.
In: International Labour Office (ILO). Proceedings of the 6th International Pneumoconiosis Conference. Geneva: (ILO); 1984. p 830-6.

5. Sheers G, Coles RM. Asbestos-associated disease in employees of Devonport dockyard. Ann NY Acad Sci 1979;330: 281-8.

6. Harries PG. The effects and control of diseases associated with exposure to asbestos in Devonport Dockyard. Gosport, Hants (UK): Institute of Naval Medicine; 1971. RN clinical research working party report, no $1 / 71$.

7. Harries PG. Asbestos hazards in naval dockyards. Ann Occup Hyg 1968;11:135-45.

8. Wagner JC, Moncrieff CB, Coles R, Griffiths DM, Munday DE. Correlation between fibre content of the lungs and disease in naval dockyard workers. Br J Ind Med 1986;43:391-5.

Received for publication: 22 August 2002 